CONGENITAL HEART DISEASE

\title{
Long term somatic growth after repair of tetralogy of Fallot: evidence for restoration of genetic growth potential
}

\author{
M M H Cheung, A M Davis, J L Wilkinson, R G Weintraub
}

Heart 2003;89:1340-1343

See end of article for authors' affiliations

......................

Correspondence to:

Dr R Weintraub,

Department of Cardiology, Royal Children's Hospital, Flemington Road,

Parkville, Victoria 3052,

Australia;

robert.weintraub@

rch.org.au

Accepted 9 June 2003
Objective: To compare actual with predicted long term growth after early repair of tetralogy of Fallot (TOF).

Design: Serial preoperative and postoperative anthropometric data were converted with $z$ scores. The presence of restrictive physiology was assessed by echocardiography.

Patients: 45 otherwise healthy patients who underwent repair at median age 1.6 years (range 0.2-4.9) were studied. Predicted height was determined from mid-parental height corrected for sex.

Results: Mean (SD) weight and height $z$ scores at the time of surgery were significantly depressed $(-1.04$ $(0.82)$ and $-0.93(0.95)$, respectively; $p<0.0001$ for both). At latest follow up at a median age of 14.2 years (range 11-20.5), mean weight and height $z$ scores were $0.16(1.1)$ and $-0.05(0.81)(p=0.32$ and $p=0.41$, respectively). The improvement between surgical and late weight and height $z$ scores was significant ( $p<0.0001$ for each comparison). Catch up growth was largely complete within two years. Age at correction, duration of follow up, and prior surgical procedures were unrelated to growth. Mean current height $\mathrm{z}$ scores were similar to those predicted by mid-parental height. Patients with restrictive right ventricular physiology $(n=24)$ had a significantly greater late $z$ score for weight $(0.49 v-0.34$; $p=0.01$ ), with a similar trend for height. Low birth weight patients experienced comparable catch up growth but remained shorter than patients with normal birth weight (mean height $z$ score $-0.64 v 0.06$; $\mathrm{p}=0.03$ ).

Conclusions: Early repair of TOF results in significant acceleration of weight and height, with normalisation of long term growth and fulfilment of genetic growth potential.
$\mathrm{P}$ oor growth frequently accompanies congenital heart disease and may be due to multiple cardiac and extracardiac causes. ${ }^{1-3}$ Historical cross sectional studies have indicated that more than $50 \%$ of patients with untreated major cardiac malformations will fall below the 16th centile for height and weight individually, and that $25-30 \%$ will fall below the third centile for both parameters. ${ }^{1}$

The benefits of surgical repair on long term growth in such children have been variable. Surgery undertaken beyond infancy has often been associated with a residual degree of growth impairment. On the other hand, normal birth weight children with isolated cardiac malformations such as ventricular septal defect (VSD) and transposition of the great arteries (TGA) that are amenable to complete and early surgical repair usually grow normally after the operation. $^{45}$

The long term growth of children with tetralogy of Fallot (TOF) undergoing early surgical repair before mid-childhood $(<5$ years of age) and with current techniques has not been studied in detail. In contrast to both TGA and VSD, this lesion is typically not repaired in the neonatal period and late haemodynamic sequelae are not uncommon. Previous studies examining the growth of children after TOF repair have reported an inconsistent and often incomplete degree of catch up growth. ${ }^{67}$ In the present surgical era, the technique of transatrial-transpulmonary repair with a conservative approach to pulmonary valve function avoids the use of an extensive right ventriculotomy, with proposed benefits that include a lower incidence of both postoperative pulmonary regurgitation and important cardiac arrhythmias. This study examined the late postoperative growth of the first cohort of children with TOF to have undergone transatrial-transpulmonary repair in our institution.

\section{METHODS}

Consecutive patients resident in the Australian state of Victoria with TOF repaired before the age of 5 years, between 1981 and 1990, were invited to participate in the study. Patients with significant extracardiac or chromosomal abnormalities and those with atrioventricular septal defect in addition to TOF were not recruited into the study. All prospective patients had a fluorescence in situ hybridisation test for chromosomal 22q11 microdeletion.

Anthropometric data were obtained from childhood community health record books, which are issued to every newborn and updated by health carers and community nurses. Perioperative data were taken from perfusion records. Additional postoperative weight and height measurements were collected from outpatient clinic visits. These data were converted to $\mathrm{z}$ scores by using standard growth data. ${ }^{8}$ Mean $\mathrm{z}$ scores were calculated by summation of individual z scores, and the change in mean $z$ scores at different time points was calculated by summating the changes in individual z scores. Low birth weight was defined as a birth $\mathrm{z}$ score below -1.28 (corresponding to the 10th centile for gestational age). Parental height was also measured at the time of assessment. The predicted height of patients was calculated by the standard formula for mid-parental height and then corrected for sex. ${ }^{9}$

Echocardiography was performed with a Hewlett Packard 5500 (Hewlett Packard, Andover, Massachusetts, USA) with ECG and respiratory monitoring. The presence of restrictive right ventricular (RV) physiology was defined as significant

Abbreviations: RV, right ventricular; TGA, transposition of the great arteries; TOF, tetralogy of Fallot; VSD, ventricular septal defect 
antegrade diastolic flow in the pulmonary artery coincident with atrial systole and present throughout the respiratory cycle, resulting in cessation of pulmonary regurgitant flow. ${ }^{10}$ Pulmonary regurgitation was considered significant if flow reversal in the distal branch pulmonary arteries was present on colour flow mapping.

Abnormally distributed data sets were described by the median (range) and normally distributed data sets by mean (SD). A $t$ test was used to compare mean z scores between groups and at different times, as well as with the reference normal population with a mean of $0 .{ }^{11}$ A probability value of $\mathrm{p}<0.05$ was considered significant.

\section{RESULTS}

Among 49 patients available for study, three were excluded from further analysis because of the presence of a $22 \mathrm{qll}$ microdeletion and one patient because of chronic bronchiectasis. Table 1 lists the characteristics of the remaining 45 patients who constituted the study population. At latest follow up three patients had estimated peak instantaneous Doppler gradients across the RV outflow tract $>40 \mathrm{~mm} \mathrm{Hg}$ and these were excluded from the analysis for restrictive physiology, which was documented in 24 of the remaining 42 (57\%) patients.

Table 2 presents mean height and weight $\mathrm{z}$ scores at birth, surgery, and latest follow up. At birth the mean weight $\mathrm{z}$ scores were -0.20 and mean length $\mathrm{z}$ scores were -0.57 . By the time of surgery, mean weight and height $\mathrm{z}$ scores were comparably depressed at -1.04 and -0.93 , respectively. Mean preoperative weight and height z scores compared with those of a normal population (mean $\mathrm{z}$ score 0 ) were significantly depressed ( $p<0.0001$ for both). At latest follow up, the mean weight and height $\mathrm{z}$ scores were not significantly different from those of the normal population $(\mathrm{p}=0.32$ and $\mathrm{p}=0.41$, respectively). The differences between the surgical and postoperative weight and height $\mathrm{z}$ scores were highly significant ( $p<0.0001$ for each) (table 2 ). Growth parameters at each time period were unrelated to age at surgical repair, need for prior surgical palliation, or duration of follow up. Mean follow up height $\mathrm{z}$ scores were marginally greater than those predicted by mid-parental height (actual -0.05 , predicted $-0.37 ; \mathrm{p}=0.05$ ). Patients with restrictive RV physiology $(\mathrm{n}=24)$ had a significantly greater mean $\mathrm{z}$ score for weight $(0.49 v-0.34 ; \mathrm{p}=0.01)$, with a similar but non-significant trend for height $(0.78 \mathrm{v}$ $-0.29 ; p=0.16$ ), than those without restrictive physiology at latest follow up. The mean body mass index of patients with and those without restrictive physiology were not significantly different $\left(21.8 \mathrm{~kg} / \mathrm{m}^{2} v 19.8 \mathrm{~kg} / \mathrm{m}^{2}\right.$, respectively; $\mathrm{p}=0.13$ ).

Table 3 shows a comparison of mean weight and height $\mathrm{z}$ scores between normal and low birth weight patients separately at the time of surgery and at latest follow up. At latest follow up, mean weight and height $\mathrm{z}$ scores of normal

\section{Table 1 Characteristics of the study population}

\begin{tabular}{ll}
\hline Sex (male:female) & $29: 16$ \\
Low birth weight for gestational age & $8(17.8 \%)$ \\
Median age in years at surgery (range) & $1.6(0.2-4.9)$ \\
Median age in years at follow up (range) & $14.2(11.0-20.5)$ \\
Median follow up duration in years (range) & $11.6(9.4-17.3)$ \\
Prior systemic pulmonary shunt & $23(51 \%)$ \\
Residual RVOTO $>40 \mathrm{~mm} \mathrm{Hg}$ & $3(7 \%)$ \\
Significant pulmonary regurgitation & $7(16 \%)$ \\
Restrictive RV physiology & $24(57 \%)$ \\
Median haemoglobin (g/l) at surgery (range) & $144(101-182)$ \\
\hline
\end{tabular}

RV, right ventricular; RVOTO, right ventricular outflow tract obstruction.
Table 2 Mean weight and height $\mathrm{z}$ scores at birth, surgical correction and latest follow up for all patients

\begin{tabular}{lcc}
\hline Parameter & Mean (SD) & p Value* \\
\hline Weight z score at birth & $-0.20(1.2)$ & 0.33 \\
Height z score at birth & $-0.57(1.0)$ & 0.0002 \\
Weight z score at operation & $-1.04(0.8)$ & $<0.0001$ \\
Height z score at operation & $-0.93(1.0)$ & $<0.0001$ \\
Current weight z score & $0.16(1.1) \dagger$ & 0.32 \\
Current height z score & $-0.05(0.8) \dagger$ & 0.41
\end{tabular}

*Difference compared with normal population (mean z score 0); $\mathrm{tp}<0.0001$ compared with respective weight and height $\mathrm{z}$ scores at time of operation.

birth weight patients did not differ from those of the reference population ( $\mathrm{p}=0.10$ and $\mathrm{p}=0.71$, respectively). Both weight and height $\mathrm{z}$ scores caught up significantly in the normal and low birth weight patients $(p \leqslant 0.02$ for each comparison). At latest follow up, low birth weight patients had significantly depressed mean height $\mathrm{z}$ scores compared with the normal birth weight group $(p=0.03)$, with a smaller separation of mean weight $\mathrm{z}$ scores between the two groups $(p=0.17)$. The discrepancy in mean weight and height $\mathrm{z}$ scores for low birth weight patients was not accounted for by obesity, with a mean body mass index in this group of $20.1(4.1) \mathrm{kg} / \mathrm{m}^{2}$.

Figure 1 shows the time course of catch up growth for both weight and height. Catch up growth was fastest within the first 12 months after surgical repair and was essentially complete for both parameters by 24 months.

\section{DISCUSSION}

This study found a significant improvement in both weight and height $\mathrm{z}$ scores in children undergoing corrective surgery for TOF. Low birth weight patients experienced a similar improvement in both growth parameters, but tended to be lighter and were significantly shorter at latest follow up. Fulfilment of genetic growth potential for the overall group was confirmed by attainment of height $\mathrm{z}$ scores in the study population that were similar to those predicted by mean parental height $\mathrm{z}$ scores. Patients with restrictive physiology tended to have higher weight but not height $\mathrm{z}$ scores at latest follow up. Overall long term growth for this group was significantly better than previously reported for patients with TOF. $^{67}$

\section{Mechanisms of growth impairment}

Birth weight is low for gestational age, chromosomal anomalies, and extracardiac malformations in up to $25 \%$ of children with certain cardiac malformations and may influence growth independently of the haemodynamic disturbance. $^{3}$ In this study, exclusion of patients with extracardiac or chromosomal anomalies may have in part accounted for the observed favourable long term growth. Depressed long term linear growth among low birth weight patients, similar to the observations of the present study, has also been observed among children undergoing early repair of large VSD or an arterial switch procedure for TGA. ${ }^{45}$ It has been suggested that low birth weight in association with a cardiac malformation probably reflects an early antenatal event that continues to limit long term growth. ${ }^{3}$

Other factors that can impair postnatal growth are more closely related to the severity of the haemodynamic disturbance. These include decreased energy intake caused by feeding difficulties, increased energy expenditure, gastrointestinal malabsorption, and inefficient utilisation of energy substrates. ${ }^{3}$ The relative contribution of each of these factors may vary from one diagnostic group to another. This may explain the discordant results reported, for example, for 
Table 3 Comparison of operative and postoperative weight and height $z$ scores between normal and low birth weight patients

\begin{tabular}{lrlll}
\hline & $\begin{array}{l}\text { Normal birth } \\
\text { weight } \\
\text { (mean (SD)) }\end{array}$ & $\begin{array}{l}\text { p Value (compared } \\
\text { with reference } \\
\text { population) }\end{array}$ & $\begin{array}{l}\text { Low birth } \\
\text { weight } \\
\text { (mean (SD)) }\end{array}$ & $\begin{array}{l}\text { p Value (compared } \\
\text { with reference } \\
\text { population) }\end{array}$ \\
\hline Operative weight z score & $-1.01(0.9)$ & $<0.0001$ & $-1.24(0.4)$ & $<0.0001$ \\
Latest follow up weight z score & $0.27(1.1)$ & 0.10 & $-0.31(1.0)^{*}$ & 0.38 \\
Change in mean weight z score & $1.28(1.2)$ & $<0.0001$ & $0.93(1.2)$ & 0.001 \\
Operative height z score & $-0.82(1.0)$ & $<0.0001$ & $-1.45(0.9)$ & $<0.0001$ \\
Latest follow up height z score & $0.06(0.8)$ & 0.71 & $-0.64(0.6)^{* *}$ & 0.07 \\
Change in mean height z score & $0.86(1.1)$ & $<0.0001$ & $0.81(1.3)$ & 0.02 \\
\hline
\end{tabular}

${ }^{*} p=0.17$ and ${ }^{* *} p=0.03$ for comparison between normal and low birth weight groups at latest follow up.

resting energy expenditure. ${ }^{12}{ }^{13}$ In the present study, the relatively symmetrical depression of preoperative weight and height contrasts with the selective depression of weight seen in infants with congestive heart failure and large VSDs. ${ }^{4}$ Approximately half $(51 \%)$ of the patients in the present study underwent palliation with a systemicpulmonary shunt before surgical repair. The severity of preoperative hypoxaemia in patients with TOF is highly variable and therefore could not be accurately quantified over an extended time. However, the finding of symmetrically depressed weight and height scores at the time of surgical correction is consistent with previous observations that tissue hypoxaemia independently influences linear growth. ${ }^{3}$
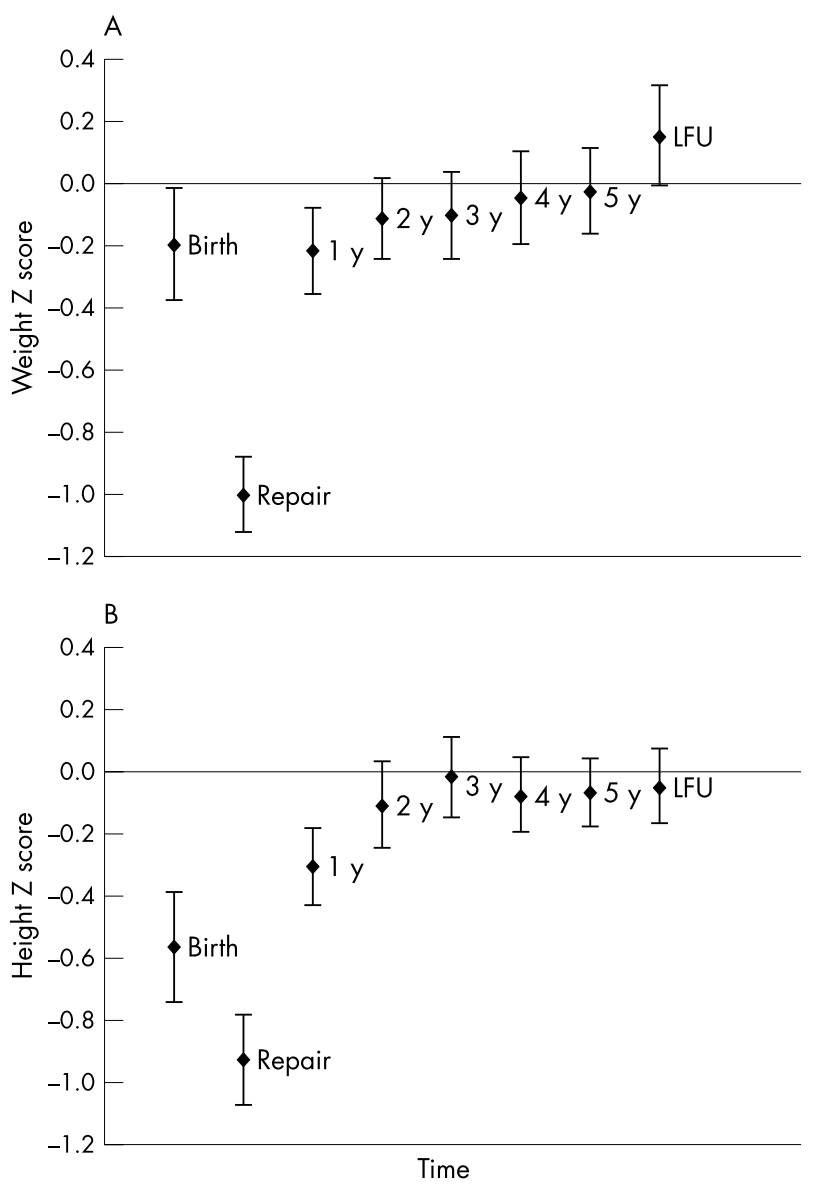

Figure 1 Serial mean (SEM) weight $z$ scores at time of birth, at operation (repair), and after surgical repair of tetralogy of Fallot (TOF). LFU, long term follow up.
Timing of surgical repair and postoperative growth Several studies have suggested that early surgical repair of cardiac defects is important in offering the best prospects for future growth. ${ }^{45}$ When surgery is undertaken beyond infancy, growth may still accelerate somewhat but the potential for catch up is limited. In the natural history study, children undergoing surgical repair of a large VSD beyond two years of age found postoperative weight gains but no improvement in mean height. ${ }^{14}$ The rate of catch up growth after repair of a large VSD has been reported to be most rapid in the first few postoperative months and in most cases completed by 6-12 months. ${ }^{3}$ Schuurmans and colleagues also showed that weight $\mathrm{z}$ scores improved most rapidly within 612 months postoperatively. ${ }^{7}$ In the present study, most catch up growth occurred during the first postoperative year but mean growth parameters continued to improve during the following year.

Among children with single ventricle physiology, conflicting results have been reported for postoperative growth after cavopulmonary connection or a modified Fontan procedure. $^{1516}$ These may well have been influenced by the heterogeneous nature of the cardiac malformations and the frequent requirement for repeated interventions, particularly in children with palliated hypoplastic left heart syndrome. ${ }^{15}$

Growth after repair of TOF has been studied less frequently. In the largest study to date, 73 children undergoing repair at a mean age of 83.3 months and followed up for at least two years were studied by Page and colleagues. ${ }^{6}$ Only 23 experienced acceleration in both postoperative weight and height, and 11 remained below the third centile for both parameters. Although patients with other medical conditions likely to affect growth were excluded, this may not have applied to patients with 22 q11 microdeletion, in view of the era of investigation. Furthermore, patients were much older at the time of surgical repair and the repair was likely to have been by a transventricular approach. The age at surgery and entry criteria in the study by Schuurmans and colleagues $^{7}$ were more directly comparable with those of our study. Interestingly, however, although growth improved, it did not normalise completely. The mean weight and height $\mathrm{z}$ scores of 11 children with repaired TOF followed up for 36-48 months were -1.22 and -0.76 , respectively, ${ }^{7}$ compared with 0.16 and -0.05 in the present study. In neither of the studies mentioned above ${ }^{67}$ was the growth of low birth weight patients examined separately.

\section{Influence of restrictive physiology}

Although restrictive RV physiology complicates the initial postoperative period after total repair of $\mathrm{TOF},{ }^{17}$ the long term benefits of this phenomenon have been well documented..$^{18} 19$ Within our population those patients with restrictive RV physiology had significantly greater $\mathrm{z}$ scores for weight at follow up. This was an unexpected finding and we did not quantify the degree of pulmonary regurgitation in sufficient 
detail to tease out this relation further. A body mass index of $22.2 \mathrm{~kg} / \mathrm{m}^{2}$ suggests that this finding was not due to a more sedentary lifestyle among those with restrictive physiology. It is also unlikely that these patients were limited by symptoms and therefore less able to exercise. ${ }^{18}$ Patients with a restrictive RV may have had more favourable haemodynamic factors resulting in better weight gain during childhood.

\section{Study limitations}

Uniform surgical techniques (transatrial-transpulmonary approach) used in our hospital for repair of TOF did not allow determination of whether conventional surgical repair involving right ventriculotomy may be associated with comparable outcomes. It was also not feasible to clarify further the impact of age of surgical intervention on postoperative growth. In the present era, many infants undergo TOF repair before 12 months of age. The benefit of this strategy on long term growth, haemodynamic status, and arrhythmia potential remain to be elucidated. In view of the finding of normal late postoperative growth in the present study, it seems unlikely that earlier surgery would have any additive benefit for long term growth.

\section{Conclusions}

Preoperative growth is depressed in children with TOF. After early transatrial-transpulmonary repair, the catch up in both height and weight is significant during the next 24 months, resulting in normalisation of long term growth and fulfilment of genetic growth potential. As with other forms of repaired congenital heart disease, with TOF low birth weight is associated with reduced linear growth at long term follow up.

\section{Authors' affiliations}

M M H Cheung, A M Davis, J L Wilkinson, R G Weintraub, Department of Cardiology, Royal Children's Hospital, Melbourne, Australia

\section{REFERENCES}

1 Mehrizi A, Drash A. Growth disturbance in congenital heart disease. J Pediatr 1962:61:418-29.

2 Linde LM, Dunn OJ, Schireson R, et al. Growth in children with congenital heart disease. J Pediatr 1967;70:413-9.

3 Weintraub RG, Menahem S. Growth and congenital heart disease. J Paediatr Child Health 1993;29:95-8.

4 Weintraub RG, . Early surgical closure of a large ventricular septal defect: influence on long-term growth. J Am Coll Cardiol 1991;18:552-8.

5 Swan JW, Weintraub RG, Radley-Smith R, et al. Long term growth following neonatal anatomic repair of transposition of the great arteries. Clin Cardiol 1993;16:392-6.

6 Page RE, Deverall PB, Watson DA, et al. Height and weight gain after total correction of Fallot's tetralogy. Br Heart J 1978;40:416-20.

7 Schuurmans FM, Pulles-Heintzberger CF, Gerver WJ, et al. Long-term growth of children with congenital heart disease: a retrospective study. Acta Paediatr 1998:87:1250-5

8 Hamill PV, Drizd TA, Johnson CL, et al. NCHS growth curves for children birth-18 years. United States. Vital Health Stat 1977;Nov: i-iv, 1-74.

9 Hay WW Jr, Hayward AR, Levin MJ, et al. Current pediatric diagnosis and treatment, 15th edn. New York: Lange Medical Books/McGraw Hill Medical Publishing Division, 2001:837.

10 Redington A, Penny D, Rigby $M$, et al. Antegrade diastolic pulmonary arterial flow as a marker right ventricular restriction after complete repair of pulmonary atresia with intact septum and critical pulmonary valve stenosis. Cardiol Young 1992;2:382-6.

11 Zar JH. Biostatistical analysis, 3rd edn. Upper Saddle River: Prentice Hall, 1996.

12 Leitch CA, Karn CA, Peppard RJ, et al. Increased energy expenditure in infants with cyanotic congenital heart disease. J Pediatr 1998;133:755-60.

13 Menon G, Poskitt EM. Why does congenital heart disease cause failure to thrive? Arch Dis Child 1985;60:1134-9.

14 Levy RJ, Rosenthal A, Miettinen OS, et al. Determinants of growth in patients with ventricular septal defect. Circulation 1978:57:793-7.

15 Stenbog EV, Hiortdal VE, Ravn HB, et al. Improvement in growth, and levels of insulin-like growth factor-l in the serum, after cavopulmonary connections. Cardiol Young 2000;10:440-6.

16 Cohen MI, Bush DM, Ferry RJ Jr, et al. Somatic growth failure after the Fontan operation. Cardiol Young 2000;10:447-57.

17 Cullen S, Shore D, Redington A. Characterization of right ventricular diastolic performance after complete repair of tetralogy of Fallot. Restrictive physiology predicts slow postoperative recovery. Circulation 1995;91:1782-9.

18 Gatzoulis MA. Clark AL, Cullen S, et al. Right ventricular diastolic function 15 to 35 years after repair of tetralogy of Fallot: restrictive physiology predicts superior exercise performance. Circulation 1995;91:1775-81.

19 Gatzoulis MA, Till JA, Somerville J, et al. Mechanoelectrical interaction in tetralogy of Fallot: QRS prolongation relates to right ventricular size and predicts malignant ventricular arrhythmias and sudden death. Circulation 1995; $92: 231-7$

\section{FROM BMJ JOURNALS}

\section{Increased Nox2 in cardiomyocytes after acute myocardial infarction}

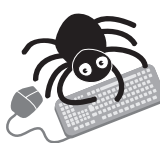

Please visit the Heart website [www.heartinl. com] for a link to the full text of this article.
Cor the first time, researchers have identified Nox2 within human cardiomyocytes and - shown that its expression increases during acute myocardial infarction.

Nox2 is an enzymatic subunit of phagocytic NADPH oxidase. It is a cell specific source of reactive oxygen species (ROS), which in turn can induce cell damage, proliferation, apoptosis, gene expression, and aging.

Investigators from the University of Amsterdam examined cardiomyocytes from infarcted and non-infarcted areas of the hearts of patients dying after an acute myocardial infarct as well as from controls without known heart disease. Western blotting and immunohistochemical techniques proved that Nox 2 was present in the plasma membrane and cytosol of cardiomyocytes. It was expressed more in infarcted than in control areas. This upregulation is probably related to production of ROS so may well play an important role in cell damage. Its precise pathophysiological role is ripe for further study.

A Journal of Clinical Pathology 2003;56:194-199. 